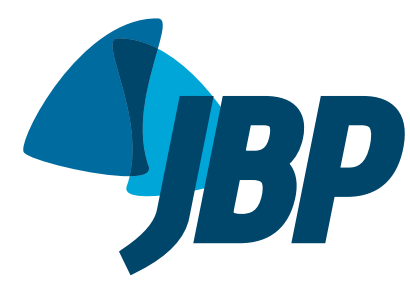

1. Serviço de Fisioterapia, Hospital de Clínicas de Porto Alegre, Porto Alegre (RS) Brasil.

2. Programa de Pós-Graduação em Ciências Pneumológicas, Faculdade de Medicina, Universidade Federal do Rio Grande do Sul, Porto Alegre (RS) Brasil.

3. Faculdade de Fisioterapia, Universidade Federal do Rio Grande do Sul, Porto Alegre (RS) Brasil.

4. Serviço de Psiquiatria, Hospital de Clínicas de Porto Alegre, Porto Alegre (RS) Brasil.

5. Serviço de Pneumologia, Hospital de Clínicas de Porto Alegre, Porto Alegre (RS) Brasil.

Submitted: 26 March 2015

Accepted: 4 August 2015.

Study carried out at the Hospital de Clínicas de Porto Alegre, Porto Alegre (RS) Brasil.

\section{Respiratory therapy: a problem among children and adolescents with cystic fibrosis}

\author{
Taiane dos Santos Feiten', Josani Silva Flores², Bruna Luciano Farias ${ }^{3}$, \\ Paula Maria Eidt Rovedder ${ }^{2,3}$, Eunice Gus Camargo ${ }^{4}$, \\ Paulo de Tarso Roth Dalcin ${ }^{2,5}$, Bruna Ziegler ${ }^{1,2}$
}

\begin{abstract}
Objective: To evaluate the level of self-reported adherence to physical therapy recommendations in pediatric patients (6-17 years) with cystic fibrosis (CF) and to ascertain whether the different levels of adherence correlate with pulmonary function, clinical aspects, and quality of life. Methods: This was a cross-sectional study. The patients and their legal guardians completed a questionnaire regarding adherence to physical therapy recommendations and a CF quality of life questionnaire. We collected demographic, spirometric, and bacteriological data, as well as recording the frequency of hospitalizations and Shwachman-Kulczycki (S-K) clinical scores. Results: We included 66 patients in the study. Mean age, $\mathrm{FEV}_{1}$ (\% of predicted), and BMI were $12.2 \pm 3.2$ years, $90 \pm 24 \%$, and $18.3 \pm 2.5 \mathrm{~kg} / \mathrm{m}^{2}$, respectively. The patients were divided into two groups: high-adherence $(n=39)$ and moderate/poor-adherence $(n=27)$. No statistically significant differences were found between the groups regarding age, gender, family income, and total S-K clinical scores. There were statistically significant differences between the high-adherence group and the moderate/poor-adherence group, the latter showing lower scores for the "radiological findings" domain of the S-K clinical score ( $p=$ $0.030)$, a greater number of hospitalizations $(p=0.004)$, and more days of hospitalization in the last year ( $p=0.012)$, as well as lower scores for the quality of life questionnaire domains emotion $(p=0.002)$, physical $(p=0.019)$, treatment burden $(p<0.001)$, health perceptions $(p=0.036)$, social $(p=0.039)$, and respiratory $(p=0.048)$. Conclusions: Low self-reported adherence to physical therapy recommendations was associated with worse radiological findings, a greater number of hospitalizations, and decreased quality of life in pediatric CF patients.
\end{abstract}

Keywords: Cystic fibrosis; Patient compliance; Physical therapy modalities; Quality of life.

\section{INTRODUCTION}

Cystic fibrosis (CF) is an autosomal recessive genetic disease characterized by chronic pulmonary infection, exocrine pancreatic insufficiency, and high concentrations of sweat electrolytes. Respiratory system changes constitute the primary cause of morbidity and mortality. ${ }^{(1-8)}$ Data from the Cystic Fibrosis Foundation show that the life expectancy of individuals with CF was 37.8 years in 2012. ${ }^{(9)}$

The standard therapeutic approach to lung disease includes antibiotic therapy, airway clearance, physical exercise, mucolytics, bronchodilators, anti-inflammatory agents, nutritional support, and oxygen supplementation. $(10,11)$ Outpatient treatment is provided by a multidisciplinary team every two or three months and is aimed at educating parents and patients regarding home treatment, monitoring disease progression, and improving treatment adherence, being adjusted as needed. ${ }^{(12)}$

Airway clearance techniques are considered essential components of the treatment of CF. In older children and adolescents, the use of techniques that prioritize their independence is encouraged. ${ }^{(13,14)}$

Flores et al. (15) studied 63 adult CF patients and showed that $40 \%$ had moderate to poor adherence to airway clearance therapies, a finding that was associated with the level of education and the severity of disease. The use of techniques preferred by patients was found to be associated with increased adherence, the level of agreement between physician-recommended therapy and self-reported adherence being highest for positive airway pressure.

In the pediatric population, poor treatment adherence is associated with patient dependence on their parents or caregivers to perform the recommended treatment techniques and a lack of understanding of the long-term implications of the disease. ${ }^{(16)}$ The difficulty that parents have in establishing a treatment routine and the use of trial and error are barriers to treatment adherence, whereas anticipatory guidance provided by a multidisciplinary team can facilitate disease management. ${ }^{(17)}$ Misconceptions, knowledge gaps, and errors regarding

Correspondence to:

Bruna Ziegler. Travessa Miranda e Castro, 70/204, Santana, CEP 90040-280, Porto Alegre, RS, Brasil.

Tel.: 5551 3335-1286. E-mail: brunaziegler@yahoo.com.br

Financial support: Bruna Luciano Farias is the recipient of a Young Investigator Grant from the Fundação de Amparo à Pesquisa do Rio Grande do Su/(FAPERGS,

Foundation for the Support of Research in the state of Rio Grande do Sul). 
CF can have an impact on disease progression. ${ }^{(18)}$ Few studies have examined adherence to therapy in patients with CF. $(15,19,20)$

A total of 2,669 patients are currently registered in the Brazilian CF Registry. Rio Grande do Sul ranks second among the Brazilian states with the highest number of CF patients, i.e., 356 individuals (13.3\%). There are currently 1,918 pediatric patients (under 18 years of age) with CF in Brazil, pediatric patients accounting for $77.6 \%$ of all CF patients in the state of Rio Grande do Sul. The number of patients diagnosed with CF has increased annually since the advent of neonatal screening for CF by immunoreactive trypsin assay. Therefore, strategies to improve treatment adherence and prevent complications are increasingly necessary. ${ }^{(21)}$

The objective of the present study was to evaluate the level of self-reported adherence to physical therapy recommendations in pediatric CF patients and to ascertain whether the different levels of adherence correlate with lung function, clinical scores, and quality of life.

\section{METHODS}

\section{Study design}

This was a cross-sectional study of pediatric CF patients. The objective of the study was to evaluate the level of adherence to respiratory therapy.

\section{Study population}

Patients with CF were recruited by the Pediatric Pulmonology Team of the Hospital de Clínicas de Porto Alegre (HCPA), located in the city of Porto Alegre, Brazil. The study sample consisted of children and adolescents in the 6- to 17-year age bracket diagnosed with CF in accordance with a consensus statement. ${ }^{(2)}$

The study sample was consecutively selected from among all patients being followed and meeting the inclusion criteria. Data were collected in the period between May and October of 2014. The study was approved by the Research Ethics Committee of the HCPA (Protocol no. 14-0157), and the parents or legal guardians of all participants gave written informed consent.

We included clinically stable patients, clinical stability being defined as no hospitalizations or changes in the maintenance therapy regimen for at least 30 days. Patients with neurological changes resulting in difficulty in completing the questionnaires were excluded.

\section{Measurements and instruments}

After having accepted the invitation to participate in the study, patients and their parents or legal guardians gave written informed consent and headed for an area outside the ambulatory care environment.

Initially, patients (accompanied by their parents or legal guardians) completed a questionnaire regarding adherence to physical therapy recommendations, developed from a previous study ${ }^{(15)}$ conducted at our referral center and consisting exclusively of objective questions, such as the following: "How many days a week and how many times a day do you perform physical therapy techniques for airway clearance?"; "How long does each session last?"; "What techniques do you perform?"; "What techniques do you like the most and what techniques do you like the least?"; "Who helps you?"; and "What are your reasons for not performing the recommended technique(s)?". Subsequently, patients completed a CF quality of life questionnaire previously validated for use in Brazil. (22) Both questionnaires were administered outside the ambulatory care environment by a professional who was not involved in the treatment of the patients. The patients themselves answered the questions, being helped by their parents or legal guardians when necessary.

Subsequently, a physical therapist who was a member of the treatment team answered the same questions, recording physical therapy recommendations for each patient.

A data collection form was used in order to gather information on the following: date; gender; age; ethnicity; family income; age at CF diagnosis; BMI; resting $\mathrm{SpO}_{2}$; sputum bacteriology; lung function; frequency of hospitalizations in the previous year (information collected from the electronic medical records of the participants, the day on which the questionnaires were administered being used in order to mark the end of the one-year period); and Shwachman-Kulczycki (S-K) clinical scores. ${ }^{(23)}$

The pulmonary function test results used in the present study were those of the spirometry tests requested in routine clinical care. Spirometry was performed at the Pulmonary Physiology Clinic of the HCPA Department of Pulmonology, with the patient in the sitting position. A v4.31a spirometer (Jaeger, Würzburg, Germany) was used, and all tests were performed in accordance with the technical acceptability criteria recommended in the Brazilian Thoracic Association guidelines for pulmonary function testing. ${ }^{(24)}$ Values of FVC, FEV ${ }_{1}$, and $\mathrm{FEV}_{1} / \mathrm{FVC}$ were recorded. All parameters were also expressed as a percentage of the predicted values for age, height, and gender. ${ }^{(25)}$

\section{Statistical analysis}

Data were entered into a Microsoft Excel 2011 database, after which they were processed and analyzed with the Statistical Package for the Social Sciences, version 18.0 (SPSS Inc., Chicago, IL, USA).

On the basis of their answers to questions regarding adherence to physical therapy recommendations in the last two weeks, patients were divided into three groups: the high-adherence group (which included patients who always performed the airway clearance techniques recommended by the physical therapist and rarely failed to undergo the recommended number of sessions); the moderate-adherence group (which included patients who always performed the airway clearance techniques recommended by the physical 
therapist but often failed to undergo the recommended number of sessions); and the poor-adherence group (which included patients who never or almost never performed the airway clearance techniques recommended by the physical therapist and never or almost never underwent the recommended number of sessions). For analysis purposes, the high-adherence group was compared with the moderate/poor-adherence group.

Quantitative data were expressed as mean and standard deviation or as median (interquartile range). Qualitative data were expressed as frequency and proportion.

Continuous variables were compared by the independent sample t-test. Ordinal variables or continuous variables without normal distribution were compared by the Wilcoxon signed-rank test. Qualitative data were analyzed with the chi-square test, Yates' correction or Fisher's exact test being used when necessary. The kappa coefficient of agreement was used in order to assess the level of agreement between physician-recommended therapy and self-reported adherence. All statistical tests were two-tailed, and the level of significance was set at $\mathrm{p}<0.05$.

In order to calculate the sample size, proportions between the high-adherence and moderate/ poor-adherence groups were taken into consideration. For an expected $40 \%$ proportion of patients with moderate/poor adherence ${ }^{(15)}-a$ total amplitude of 0.25 and a $95 \%$ confidence interval being used-the minimum sample size was calculated to be $59 .{ }^{(26)}$

\section{RESULTS}

During the study period, the HCPA Pediatric Pulmonology Team followed a total of 109 patients with CF. Of those, 72 were between 6 and 17 years of age. Of those 72 patients, 66 were included in the study and evaluated. Two patients were excluded from the study: one was excluded because of pulmonary exacerbation requiring hospitalization, and the other was excluded because the parents did not allow the patient to participate in the study. Another 4 patients failed to return for follow-up during the study period.

On the basis of self-reported adherence, patients were divided into two groups for analysis: the high-adherence group (comprising 39 patients and accounting for $59 \%$ of the sample as a whole); and the moderate/ poor-adherence group (comprising 27 patients and accounting for $41 \%$ of the sample as a whole).

Table 1. General characteristics of pediatric patients with cystic fibrosis, by level of adherence to respiratory therapy. ${ }^{\mathrm{a}}$

\begin{tabular}{|c|c|c|c|}
\hline p & $\begin{array}{l}\text { Moderate/poor adherence } \\
\qquad(n=27)\end{array}$ & $\begin{array}{l}\text { High adherence } \\
\qquad(\mathrm{n}=39)\end{array}$ & Variable \\
\hline 0.139 & $12.9 \pm 3.6$ & $11.7 \pm 2.8$ & Age, years \\
\hline 0.372 & $0.33(1)$ & $0.25(3)$ & Age at diagnosis, years ${ }^{b}$ \\
\hline 0.179 & $10 / 17$ & $21 / 18$ & Male/Female, $n / n$ \\
\hline 0.336 & $18.7 \pm 3.1$ & $18.0 \pm 2.0$ & $\begin{array}{l}\mathrm{BMI}, \mathrm{kg} / \mathrm{m}^{2} \\
\text { Sputum bacteriology }\end{array}$ \\
\hline 0.791 & $20(74.1)$ & 30 (76.9) & MSSA \\
\hline 0.483 & $2(7.4)$ & $5(12.8)$ & MRSA \\
\hline 0.715 & $14(51.8)$ & $22(56.4)$ & Pseudomonas aeruginosa \\
\hline 0.290 & 7 (25.9) & $6(15.3)$ & Burkholderia cepacia \\
\hline 0.222 & & & Family income ${ }^{c}$ \\
\hline & $11(40.7)$ & $24(61.5)$ & $<3 \times$ the national minimum wage \\
\hline & $6(22.2)$ & 7 (17.9) & $3-5 \times$ the national minimum wage \\
\hline & $9(33.3)$ & 7 (17.9) & $>5 \times$ the national minimum wage \\
\hline 0.184 & $74.2 \pm 12.8$ & $78.8 \pm 14.1$ & Total S-K score \\
\hline 0.030 & $12.0 \pm 4.8$ & $15.0 \pm 5.9$ & $\begin{array}{l}\text { S-K radiological findings domain, score } \\
\text { Quality of life score domains, score }\end{array}$ \\
\hline 0.019 & $72 \pm 21.1$ & $84.3 \pm 15.9$ & Physical \\
\hline 0.088 & $68.3 \pm 16.5$ & $81.4 \pm 14.8$ & Vitality \\
\hline 0.002 & $69.4 \pm 16.6$ & $82.2 \pm 12.6$ & Emotion \\
\hline 0.180 & $76.7 \pm 30.2$ & $86.5 \pm 15.6$ & Eating \\
\hline 0.000 & $55.0 \pm 24.7$ & $82.4 \pm 14.9$ & Treatment burden \\
\hline 0.036 & $70.0 \pm 18.9$ & $87.6 \pm 14.1$ & Health perceptions \\
\hline 0.039 & $67.5 \pm 19.4$ & $78.2 \pm 17.3$ & Social \\
\hline 0.155 & $78.3 \pm 27.0$ & $87.2 \pm 18.2$ & Body image \\
\hline 0.158 & $76.6 \pm 19.5$ & $88.8 \pm 16.1$ & Social role \\
\hline 0.964 & $73.3 \pm 37.8$ & $74.0 \pm 32.3$ & Weight \\
\hline 0.048 & $64.4 \pm 21.0$ & $75.3 \pm 18.1$ & Respiratory \\
\hline
\end{tabular}

MSSA: methicillin-susceptible Staphylococcus aureus; MRSA: methicillin-resistant Staphylococcus aureus; and S-K: Shwachman-Kulczycki. aValues expressed as mean $\pm S D$, except where otherwise indicated. bValue expressed as median (interquartile range). 'Values expressed as $\mathrm{n}(\%)$. 
Table 1 presents the general characteristics of the CF patients in the present study, by level of self-reported adherence to respiratory therapy. There were no statistically significant differences between the groups regarding age, gender, family income, or total S-K clinical scores. When the "radiological findings" domain of the S-K clinical score was analyzed separately, scores were found to be significantly lower in the moderate/ poor-adherence group than in the high-adherence group $(p=0.030)$.

The moderate/poor-adherence group had significantly lower scores for the quality of life questionnaire domains emotion $(p=0.002)$, physical $(p=0.019)$, treatment burden $(p<0.001)$, health perceptions $(p=0.036)$, social ( $p=0.039)$, and respiratory $(p=0.048)$.

Table 2 shows pulmonary function test results and frequency of hospitalizations (number of hospitalizations in the last year and number of days hospitalized in the last year) in the CF patients studied, by level of self-reported adherence to respiratory therapy. There were no statistically significant differences between the groups regarding lung function variables. However, the mean number of hospitalizations in the last year and the mean number of days hospitalized in the last year were significantly higher in the poor/moderate-adherence group than in the high-adherence group ( $p=0.004$ and $\mathrm{p}=0.012$, respectively).

Table 3 shows self-reported reasons for not performing the recommended physical therapy techniques for airway clearance. Feeling tired and not liking the recommended technique were reported significantly more often in the moderate/poor-adherence group than in the high-adherence group ( $p=0.002$ for both); in contrast, having some other engagement was reported significantly more often in the high-adherence group than in the poor/moderate-adherence group ( $p<0.001)$.

Of the 66 patients studied, $52(78.8 \%)$ were supervised by their mothers, 25 (37.9\%) were supervised by their fathers, and $4(6.1 \%)$ were supervised by a physical therapist, whereas 26 (39.4\%) performed the recommended techniques without supervision. When answering the question regarding assistance when performing the recommended physical therapy techniques for airway clearance, patients were allowed to select more than one response (i.e., more than one supervisor). There were no statistically significant differences between the groups regarding the aforementioned variable.

The most commonly used respiratory therapy techniques were coughing (in 97\%), huffing (in $86.4 \%$ ), expiratory positive airway pressure (EPAP) delivered through a mask (in $84.8 \%$ ), positive expiratory pressure (PEP) on water seal (in 18.2\%), and slow exhalation to residual volume with an open glottis (in 4.5\%).

There was agreement between physician-recommended therapy and self-reported adherence for EPAP mask (kappa $=0.63 ; p<0.001$ ) and PEP on water seal (kappa $=0.54 ; p<0.001)$, The level of agreement between physician-recommended therapy and self-reported adherence was not significant for huffing, coughing, and slow exhalation to residual volume with an open glottis.

\section{DISCUSSION}

The present study included 66 pediatric CF patients followed by the HCPA Pediatric Pulmonology Team in order to evaluate the level of adherence to physical therapy recommendations. This was the first study to evaluate adherence to respiratory therapy in pediatric CF patients in Brazil. To that end, we used a questionnaire developed from a previous study conducted under the auspices of the HCPA Program for Adults with CF. Of the sample as a whole, $59 \%$ were in the high-adherence group and $41 \%$ were in the moderate/poor-adherence group.

Flores et al. ${ }^{(15)}$ studied 63 patients enrolled in the HCPA Program for Adults with CF (mean age, 23.1 years) in order to evaluate adherence to respiratory therapy techniques. They found high adherence in $60 \%$ of the sample as a whole and moderate/poor adherence in $40 \%$, findings that are similar to ours. This allows us to assume that, during childhood, patients develop a treatment adherence pattern that remains throughout adolescence and adulthood.

In our study, there were no differences between the high-adherence and moderate/poor-adherence groups

Table 2. Lung function and hospitalizations in pediatric patients with cystic fibrosis, by level of adherence to respiratory therapy. ${ }^{a}$

\begin{tabular}{cccl}
$\mathbf{p}$ & $\begin{array}{c}\text { Moderate/poor } \\
\text { adherence } \\
\text { (n }=\mathbf{2 7})\end{array}$ & $\begin{array}{c}\text { High adherence } \\
\text { (n }=39)\end{array}$ & \multicolumn{1}{c}{ Variable } \\
\hline 0.433 & $2.8 \pm 1.3$ & $2.6 \pm 0.9$ & $\mathrm{FVC}, \mathrm{l}$ \\
0.657 & $93.6 \pm 21.1$ & $95.9 \pm 20.1$ & $\mathrm{FVC}, \%$ of predicted \\
0.535 & $2.2 \pm 1.1$ & $2.1 \pm 0.7$ & $\mathrm{FEV}_{1}, \mathrm{l}$ \\
0.352 & $86.6 \pm 22.8$ & $92.3 \pm 24.8$ & $\mathrm{FEV}_{1}, \%$ of predicted \\
0.326 & $80.2 \pm 11.4$ & $82.8 \pm 9.4$ & $\mathrm{FEV}_{1} / \mathrm{FVC}$ \\
0.354 & $95.0 \pm 13.6$ & $97.9 \pm 10.9$ & $\mathrm{FEV}_{1} / \mathrm{FVC} \%$ of predicted \\
0.421 & $97.6 \pm 1.7$ & $98.0 \pm 1.7$ & Resting SpO $_{2}$, \% \\
0.004 & $1.4(1.3)$ & $0.5(0.8)$ & No. of hospitalizations in the last year \\
0.012 & $29.5(38.5)$ & $8.5(16.3)$ & No. of days hospitalized in the last year ${ }^{\mathrm{b}}$ \\
\hline
\end{tabular}

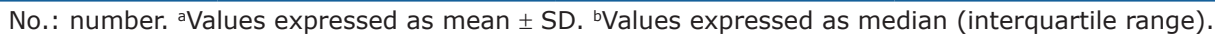


Table 3. Reasons for not performing the recommended physical therapy techniques for airway clearance. ${ }^{a}$

\begin{tabular}{lccc}
\multicolumn{1}{c}{ Variable } & $\begin{array}{c}\text { Moderate/poor adherence } \\
\text { (n = 27) }\end{array}$ & $\begin{array}{c}\text { High adherence } \\
\text { (n = 39) }\end{array}$ & $\mathbf{p}$ \\
\hline Lack of time & $10(25.6)$ & $13(48.1)$ & 0.059 \\
Cannot be bothered & $1(2.5)$ & $5(18.5)$ & 0.038 \\
Feels tired & $1(2.5)$ & $8(29.6)$ & 0.002 \\
Does not like it & $1(2.5)$ & $8(29.6)$ & 0.002 \\
Cannot find any motivation & $0(0.0)$ & $4(14.8)$ & 0.024 \\
Other engagements & $31(79.4)$ & $8(29.6)$ & 0.000 \\
\hline
\end{tabular}

avalues expressed as $\mathrm{n}(\%)$.

regarding age, age at diagnosis, family income, total S-K clinical scores, sputum bacteriology, BMI, or lung function. However, when the "radiological findings" domain of the S-K clinical score was analyzed separately, scores were found to be significantly lower in the moderate/poor-adherence group. Arias Llorente et al. (27) evaluated adherence to treatment in a sample of $34 \mathrm{CF}$ patients (including adult and pediatric patients) and found that S-K clinical scores were significantly higher in those who showed greater adherence to physical therapy recommendations. Flores et al.(15) found significantly lower S-K clinical scores and lung function in the group of patients who showed high adherence to physical therapy recommendations. This difference is due to the fact that adult patients present with disease that is more severe and therefore require greater adherence to treatment.

In our study, the high-adherence group showed higher scores for the quality of life questionnaire domains emotion, physical, treatment burden, health perceptions, social, and respiratory. A study conducted at the Hospital de Clínicas de Campinas, in the city of Campinas, Brazil, evaluated the quality of life of pediatric patients with CF and showed that patients with lower S-K clinical scores $(<70)$ had lower scores for the quality of life questionnaire domains social, respiratory, and digestive. ${ }^{(28)}$

In the present study, the most commonly used respiratory therapy techniques were coughing, huffing, and EPAP mask. The level of agreement between the two questionnaires was highest for EPAP and PEP on water seal. In contrast, Flores et al. ${ }^{(15)}$ found that active cycle of breathing was the most commonly used technique in adults with CF (79.4\%). This difference between pediatric/young patients and adult patients is probably due to the fact that the former require adult supervision in order to perform respiratory therapy techniques, and EPAP mask is easy to use and provides greater patient autonomy. A randomized study conducted at $12 \mathrm{CF}$ centers in Canada showed that EPAP mask was superior to high-frequency chest wall oscillation in patients followed for one year. The number of pulmonary exacerbations was nearly twice as high in those who used high-frequency chest wall oscillation, and those who used EPAP less often required antibiotics. ${ }^{(29)}$

In 2010, Modi et al. ${ }^{(30)}$ studied 153 patients (mean age, 14 years) in order to evaluate adherence to respiratory therapy. Patients completed a daily telephone diary and reported their level of adherence every four months. Of the sample as whole, $37 \%$ were assigned to the high-adherence group, $49 \%$ were assigned to the moderate-adherence group, and $14 \%$ were assigned to the poor-adherence group. The type of airway clearance technique was the only predictor of adherence, and high-frequency chest wall oscillation was the technique preferred by patients, being associated with greater adherence. The levels of adherence in the aforementioned study are not comparable to those in ours, given that the data collection instruments were different; nevertheless, the technique preferred by patients was associated with greater adherence in both studies.

In 2009, Bucks et al. (31) evaluated 38 adolescents with $\mathrm{CF}$, analyzing the factors that had an impact on treatment adherence. According to the authors, nonadherence to respiratory therapy was associated with the way in which patients judged their personal need for treatment.

In the present study, the most common reasons for not performing the recommended physical therapy techniques for airway clearance included having other engagements, feeling tired, and not liking the technique (the first in the high-adherence group and the last two in the moderate/poor-adherence group). Flores et al. ${ }^{(15)}$ found that the most common reason for not performing the recommended physical therapy techniques for airway clearance was lack of time. This difference might be due to the lifestyle of adults, who are encouraged to have social and work activities. In the study by Arias Llorente et al., (27) self-reported adherence to physical therapy was $41.2 \%$, being the lowest among all treatments studied. The most common reason for not performing physical therapy was lack of time. Adherence was greater among the patients who had more than one option of physical therapy technique to choose from.

The limitations of the present study are primarily related to the cross-sectional design and the inclusion of pediatric/young patients covering a wide age range and having different levels of understanding, as well as to the fact that adherence to physical therapy recommendations was self-reported, which is generally associated with higher adherence scores. The fact that the questionnaire regarding adherence to physical therapy recommendations used in the present study has yet to be validated might have biased the study 
results. Future studies should examine parental education level and psychological aspects.

In conclusion, the present study showed that $59 \%$ of the pediatric CF patients studied had high adherence to physical therapy recommendations, whereas approximately $41 \%$ failed to follow such recommendations, other engagements and tiredness being the most common reasons for not performing the recommended techniques for airway clearance. These findings indicate a problem that deserves attention and provide the basis for strategies to improve patient adherence to physical therapy recommendations. Low self-reported adherence to physical therapy recommendations was associated with worse radiological findings, a greater number of hospitalizations, and decreased quality of life. There was no association between adherence to physical therapy recommendations and lung function.

\section{ACKNOWLEDGMENTS}

We would like to thank the entire HCPA CF team and the collaborators who made the present study possible.

\section{REFERENCES}

1. Rosenstein BJ. What is a cystic fibrosis diagnosis? Clin Chest Med. 1998;19(3):423-41， v. http://dx.doi.org/10.1016/S0272 5231(05)70091-5

2. Rosenstein BJ, Cutting GR. The diagnosis of cystic fibrosis: a consensus statement. Cystic Fibrosis Foundation Consensus Panel. J Pediatr. 1998;132(4):589-95. http://dx.doi.org/10.1016/S0022 3476(98)70344-0

3. Noone PG, Knowles MR. Standard therapy of cystic fibrosis lung disease. In: Yankaskas JR, Knowles MR, editors. Cystic fibrosis in adults. Philadelphia: Lippincott Williams \& Wilkins; 1999. p. 145-73.

4. Orenstein DM, Winnie GB, Altman H. Cystic fibrosis: a 2002 update. J Pediatr. 2002;140(2):156-64. http://dx.doi.org/10.1067/ mpd.2002.120269

5. Santos $\mathrm{Cl}$, Ribeiro JD, Ribeiro AF, Hessel G. Critical analysis of scoring systems used in the assessment of Cystic Fibrosis severity: State of the art [Article in Portuguese]. J Bras Pneumol. 2004;30(3):286-98.

6. Langer D, Gosselink R, Pitta F, Burtin C, Verleden G, Dupont L, et al. Physical activity in daily life 1 year after lung transplantation. $J$ Heart Lung Transplant. 2009;28(6):572-8. http://dx.doi.org/10.1016/ healun.2009.03.007

7. Ihle $F$, Neurohr $C$, Huppmann $P$, Zimmermann G, Leuchte $H$, Baumgartner $R$, et al. Effect of inpatient rehabilitation on quality of life and exercise capacity in long-term lung transplant survivors: a prospective, randomized study. J Heart Lung Transplant 2011;30(8):912-9. http://dx.doi.org/10.1016/j.healun.2011.02.006

8. Flume PA, Van Devanter DR. State of progress in treating cystic fibrosis respiratory disease. BMC Med. 2012;10:88. http://dx.doi org/10.1186/1741-7015-10-88

9. Cystic Fibrosis Foundation. Cystic Fibrosis Foundation Patien Registry. 2012 Annual Data Report. Bethesda: Cystic Fibrosis Foundation; 2013

10. Yankaskas JR, Marshall BC, Sufian B, Simon RH, Rodman D. Cystic fibrosis adult care: consensus conference report. Chest. 2004;125(1 Suppl):1S-39S. http://dx.doi.org/10.1378/chest.125.1_suppl.1S

11. Gibson RL, Burns JL, Ramsey BW. Pathophysiology and management of pulmonary infections in cystic fibrosis. Am J Respir Crit Care Med. 2003;168(8):918-51. http://dx.doi.org/10.1164/rccm.200304-505SO

12. Abarno CP, Laurent MC, Ribeiro NR, Abreu e Silva FA. Characteristics of children and adolescents with cystic fibrosis followed up in a reference center in south Brazil [Article in Portuguese]. Rev HCPA 2011;31(2):145-50

13. Dodd JD, Barry SC, Barry RB, Gallagher CG, Skehan SJ, Masterson JB. Thin-section CT in patients with cystic fibrosis: correlation with peak exercise capacity and body mass index. Radiology. 2006;240(1):236-45. http://dx.doi.org/10.1148/radiol.2401050502

14. Marshall BC, Samuelson WM. Basic therapies in cystic fibrosis. Does standard therapy work? Clin Chest Med. 1998;19(3):487-504, vi. http://dx.doi.org/10.1016/S0272-5231(05)70095-2

15. Flores JS, Teixeira FÂ, Rovedder PM, Ziegler B, Dalcin Pde T Adherence to airway clearance therapies by adult cystic fibrosis patients. Respir Care, 2013;58(2):279-85. http://dx.doi.org/10.4187/ respcare.01389

16. Everhart RS, Fiese BH, Smyth JM, Borschuk A, Anbar RD. Family
Functioning and Treatment Adherence in Children and Adolescents with Cystic Fibrosis. Pediatr Allergy Immunol Pulmonol. 2014;27(2)826. http://dx.doi.org/10.1089/ped.2014.0327

17. Grossoehme DH, Filigno SS, Bishop M. Parent routines for managing cystic fibrosis in children. J Clin Psychol Med Settings. 2014;21(2):125-35. http://dx.doi.org/10.1007/s10880-014-9396-1

18. Chomik S, Klincewicz B, Cichy W. Disease specific knowledge about cystic fibrosis, patient education and counselling in Poland. Ann Agric Environ Med. 2014;21(2):420-4. http://dx.doi.org/10.5604/1232 1966.1108617

19. Reiners AA, Azevedo RC, Vieira MA, Arruda AL. Bibliographic production about adherence/non-adherence to therapy [Article in Portuguese]. Cienc Saude Coletiva. 2008;13(2):2299-2306. http:// dx.doi.org/10.1590/S1413-81232008000900034

20. Machado CA. Adherence to therapies--current theme. Rev Bras Hipertens. 2008;15(4):220-1.

21. Grupo Brasileiro de Estudos de Fibrose Cística [homepage on the Internet]. São Paulo: GBEFC; c2015 [cited 2015 Mar 23]. Registro Brasileiro de Fibrose Cística 2012. [Adobe Acrobat document, 60p.] Available from: http://www.gbefc.org.br/gbefc/Registro_Portugues. pdf

22. Rozov T, Cunha MT, Nascimento O, Quittner AL, Jardim JR. Linguistic validation of cystic fibrosis quality of life questionnaires. J Pediatr (Rio J). 2006;82(2):151-6. http://dx.doi.org/10.2223/JPED.1463

23. SHWACHMAN H, KULCZYCKI LL. Long-term study of one hundred five patients with cystic fibrosis; studies made over a five- to fourteen-year period. AMA J Dis Child. 1958;96(1):6-15. http://dx.doi. org/10.1001/archpedi.1958.02060060008002

24. Sociedade Brasileira de Pneumologia e Tisiologia. Diretrizes para Testes de Função Pulmonar. J Pneumol. 2002;28(Suppl 3):S1-S238.

25. Pereira CA. Spirometry [Article in Portuguese]. J Pneumol. 2002;28(Suppl 3):S1-S82

26. Hulley SB, Cummings SR, Browner WS, Grady D, Hearst N, Newman TB. Designing Clinical Research: An Epidemiologic Approach. 2nd ed. Philadelphia: Lippincott Williams \& Wilkins; 2001.

27. Arias Llorente RP, Bousoño García C, Díaz Martín JJ. Treatment compliance in children and adults with cystic fibrosis. J Cyst Fibros. 2008;7(5):359-67. http://dx.doi.org/10.1016/j.jcf.2008.01.003

28. Cohen MA, Ribeiro MÂ, Ribeiro AF, Ribeiro JD, Morcillo AM. Quality of life assessment in patients with cystic fibrosis by means of the Cystic Fibrosis Questionnaire. J Bras Pneumol. 2011;37(2):184-92.

29. Mcllwaine MP, Alarie N, Davidson GF, Lands LC, Ratjen F, Milner $\mathrm{R}$, et al. Long-term multicentre randomised controlled study of high frequency chest wall oscillation versus positive expiratory pressure mask in cystic fibrosis. Thorax. 2013;68(8):746-51.

30. Modi AC, Cassedy AE, Quittner AL, Accurso F, Sontag M, Koenig $\mathrm{JM}$, et al. Trajectories of adherence to airway clearance therapy for patients with cystic fibrosis. J Pediatr Psychol. 2010;35(9):1028-37. http://dx.doi.org/10.1093/jpepsy/jsq015

31. Bucks RS, Hawkins K, Skinner TC, Horn S, Seddon P, Horne R. Adherence to treatment in adolescents with cystic fibrosis: the role of illness perceptions and treatment beliefs. J Pediatr Psychol. 2009;34(8):893-902. http://dx.doi.org/10.1093/jpepsy/jsn135 